\title{
LIVRE EXPRESSÃO: A PERSPECTIVA FREINETIANA DE EDUCAR
}

\author{
FILHO, Aristeo Leite ${ }^{1}$
}

\begin{abstract}
"A educação não é uma fórmula de escola, mas sim uma obra de vida!" (FREINET, 1991, p. 9)
\end{abstract}

Este texto foi elaborado a partir de anotações de estudos e de aulas das quais participei, tanto como estudante quanto como professor, em cursos de formação de professores, seminários e oficinas.

Há muito tempo estudo a vida e a obra desse educador francês, crítico da escola tradicional e reformulador das teorias da Escola Nova. Descobri que sua pedagogia e suas ideias e práticas são capazes de fomentar nas nossas cabeças de professores brasileiros uma verdadeira necessidade de fazer uma revolução nas nossas escolas. Dos pedagogos contemporâneos, sem dúvida, ele é o que mais nos oferece contribuições para reinvenção da escola. Suas ideias pedagógicas são inovadoras por sua dimensão social, explícitas na defesa de uma escola centrada na criança, que é vista não como indivíduo isolado, mas fazendo parte de uma sociedade. Sua pedagogia foi sendo tecida na perspectiva da construção de uma escola viva, ativa e dinâmica e, simultaneamente, contextualizada do ponto de vista social e cultural.

Falar de Freinet e da atualidade da sua pedagogia hoje se faz muito necessário. Primeiramente, porque, não obstante a produção acadêmica sobre a Pedagogia Freinet ter crescido significativamente no Brasil nos últimos anos, ainda se fala pouco nas universidades, nos cursos de licenciaturas, sobre esse educador, suas técnicas e os princípios da sua pedagogia. $\mathrm{E}$, ainda, porque, sendo ele um inovador das práticas pedagógicas de uma escola para o povo, é tudo o que precisamos conhecer e refletir para construirmos uma escola diferente, acolhedora de crianças com as mais diversas infâncias.

O texto que segue está estruturado em três partes centrais, a saber. Na primeira, Marcas do educador, trato especificamente de algumas marcas que influenciaram as ideias e práticas tão inovadoras e revolucionárias de Célestin Freinet. Na segunda parte, Pedagogias, procuro associar os nomes pelos quais sua pedagogia ficou conhecida a alguns dos princípios que norteiam sua prática educativa. Na última, Livre expressão e seus suportes, abordo especificamente a Livre Expressão e os recursos que Freinet usava para praticá-la com as crianças. Por fim, algumas considerações instando a reinventar a escola.

\footnotetext{
${ }^{1}$ Professor Adjunto do DEDI, Departamento de Estudos da Infância da Faculdade de Educação da Universidade do Estado do Rio de Janeiro. Professor do curso de Pós-graduação em Educação Infantil da PUC-Rio. Diretor da escola Oga Mitá - RJ. Email: aristeoleitef@gmail.com
} 


\section{I - MARCAS DO EDUCADOR}

Freinet (1896-1966), educador francês, teve "uma personalidade múltipla, em permanente ebulição" (OLIVEIRA, 1995). Um dos seus amigos dizia de brincadeira que Freinet tinha pelo menos vinte ideias novas por dia. Em sua trajetória de vida, podemos identificar algumas marcas que merecem ser explicitadas para uma melhor compreensão de onde vêm suas ideias e práticas tão inovadoras e revolucionárias.

Celestin Freinet foi, verdadeiramente, um homem do seu tempo, de uma época rica de esperanças, onde os ideais progressistas, sob o impacto da Revolução de Outubro tiveram um impulso considerável. Uma época, no entanto, profundamente marcada por duas guerras e pela maior crise econômica até então vivida pelo mundo capitalista. Ao longo dos quarenta e seis anos de sua carreira, ela incarnou (sic) na sua própria vivência, muitas das lutas, avanços e recuos do corpo docente francês (OLIVEIRA, 1995, p. 91).

Antes de tudo, Freinet foi um professor primário. Foi um pacifista, participou da Primeira Guerra Mundial na condição de jovem soldado (1915), retornou com uma lesão pulmonar causada por gases tóxicos, o que comprometeu sua saúde pela vida inteira. Optou por ser professor com o intuito de acabar com as guerras no mundo.

Foi autodidata. Quando estava no terceiro ano da Escola Normal masculina, que totalizava quatro anos, foi convocado pelo governo francês para ir à guerra. Toda sua formação se deu ao longo da sua carreira como professor autodidata. Além de estudar os autores da pedagogia na busca de resolver os problemas que apareciam no cotidiano de sua classe, Freinet ia a quase todos os eventos, congressos e seminários sobre pedagogia na
Europa. Dentre muitos pensadores que estudou, baseou-se em Montaigne e Pestalozzi - com o qual demonstrou bastante afinidade. Outros estudiosos contribuíram para a formação do pensamento freinetiano, dentre eles também estão as figuras de Ferrière (a sua primeira influência), Montessori e Decroly, além de Dewey, Claparède e Makarenko (educadores do movimento escolanovista). Makarenko trouxe contribuições aos pressupostos freinetianos, ao referir-se a um trabalho coletivo e produtivo feito de fora para dentro das escolas e baseado numa pedagogia psicológica.

Freinet não teme reconhecer as contribuições dos pioneiros da Escola Nova à progressiva construção de sua obra (...). No entanto, nenhuma dessas apropriações se faz com servilidade, ou mesmo com fidelidade. Na verdade Freinet apodera-se do pensamento desses autores de uma forma que poderia ser chamada, no sentido etimológico da palavra, de "subversiva"(...) (OLIVEIRA, 1995, p. 124).

Ele foi um humanista, que lutou pela vida inteira. Primeiro, quando retornou da Primeira Guerra. Ele foi atingido fortemente com uma doença pulmonar, ficou em convalescença entre a vida e a morte. Vencendo a morte, rejeitou ser aposentado como ex-combatente jovem e foi trabalhar como professor da escola pública (1920). Depois, no campo de concentração na Segunda Guerra. Preso e mandado para o campo de concentração de Var (1940), ficou mais uma vez gravemente doente. Sua esposa Élise, com ajuda de amigos, depois de muita luta, conseguiu sua transferência para o hospital do campo de concentração. Já internado, recomeçou suas atividades educacionais: alfabetizou pessoas idosas que recebiam cartas dos seus familiares e não sabiam ler nem escrever; organizou grupos de expressão artística; criou um jornal, 
mesmo escrito à mão; escreveu peças teatrais para serem representadas pelos grupos de companheiros prisioneiros. Ainda no campo de concentração, começou a escrever seu livro Conselhos aos pais. Ao ser libertado, mais uma vez, derrota a morte.

Como internacionalista, defendia o esperanto como língua universal e não via sentido nos nacionalismos exacerbados. O seu internacionalismo socialista compreendia que a classe trabalhadora é uma só no mundo inteiro e que as divisões em países (brigas entre os burgueses que operam o Estado) não devem ser defendidas pelo povo.

Foi marxista. No início da sua carreira docente, leu as obras de Marx e de Lênin. O pensamento dialético o cativou. Ele usou as ideias desses autores para combater a filosofia positivista. Sua pedagogia é uma pedagogia do movimento, da superação de obstáculos. É uma pedagogia para o povo, para as classes populares. Sua obra é marcada por um aspecto que tem suas raízes no pensamento marxista, o "materialismo escolar". A concepção de trabalho tem um lugar importante na Pedagogia Freinet. Ele criticava o trabalho alienado e defendia uma educação de caráter politécnico, que favorecesse crianças e adolescentes a refletirem criticamente sobre as formas de exploração do trabalho e o trabalho fragmentado e alienador. Para Freinet, o trabalho é uma necessidade para os homens, não fazia distinção entre trabalho intelectual e manual. Como a maioria dos "excombatentes progressistas" dos anos 1920, ele foi filiado ao Partido Comunista Francês por muitos anos.

Influenciado pelos ideários republicano, socialista e libertário da Escola Normal que frequentou (os três primeiros anos), Freinet foi um democrata. Suas técnicas pedagógicas estavam baseadas na vivência da democracia na escola, protagonizou as chamadas Escolas Democrá- ticas. Para ele, além das técnicas pedagógicas, os aspectos político e social ao redor da escola não deveriam ser ignorados pelo professor. Dizia: "a democracia de amanhã se prepara na democracia da escola".

Foi um militante em defesa da escola pública. Um dos seus livros mais importantes se chama Uma escola para o povo. Engajado no movimento dos professores revolucionários, filiou-se ao PFC, foi dirigente sindical e escreveu vários artigos em revistas e jornais do sindicato e do partido. Freinet se envolveu em vários movimentos sociais dos quais saiu hostilizado ou perseguido. Suas ideias passaram a incomodar os conservadores franceses, e Freinet foi afastado da escola pública de Saint Paul. Após sua saída, criou uma escola privada e laica, a Escola de Vence, construída a partir de 1934 com a ajuda de doações e participação dos pais, mas o Ministério de Educação recusou-se a reconhecê-la oficialmente. Não obstante esse não reconhecimento, trabalhou sem esmorecer, criando o Conselho Cooperativo (gestão participativa), os jornais murais, a imprensa escolar, as fichas autocorretivas, a correspondência escolar, os ateliês de arte, as aulas-passeio e o Livro da Vida. Participou ativamente dos movimentos "Abaixo os manuais escolares", ocasião em que escreveu um livro com esse título. Possuidor de uma profunda consciência social, abandonou os tradicionais manuais escolares e criou com seus estudantes um material de trabalho que respondia às questões que lhes eram postas pela vida, passo a passo com a constituição de conhecimentos sobre as diferentes áreas do saber. O texto intitulado Abaixo os manuais escolares, à época, revolucionou as ideias sobre os pesados compêndios escolares que serviam de apoio à educação de crianças e adolescentes. Manuais daquele tipo, enciclopédicos, não tinham nenhuma relação com a vida e lidavam com os conteúdos de forma fragmentada. Freinet sugeria que professores 
e estudantes construíssem seus próprios textos e fichas de estudos. Outro movimento no qual ele se engajou na França foi a luta dos professores por "25 alunos no máximo por turma" (1956).

Foi cooperativista, sua prática sempre foi socializada com os colegas docentes. Foi um pioneiro na proposição de uma prática pedagógica centrada na cooperação. Seu trabalho pressupõe a cooperação não só entre os estudantes, como também entre os professores. Criou uma cooperativa de trabalho com professores (1924) de sua aldeia, e essa cooperativa suscitou o movimento da Escola Moderna na França. Criou o ICEM, Cooperativa do Ensino Leigo (final dos anos de 1940), em Vence, que reunia mais de 20 mil professores. Junto com sua esposa Élise, fundou a Federação Internacional dos Movimentos da Escola Moderna (Fimem), em 1956, que hoje reúne educadores de cerca de 50 países. Freinet morreu em 1966.

Foi um otimista e persistente por característica pessoal. Defendeu sempre a ideia de que "é preciso ter esperança otimista na vida".

\section{II - Pedagogias}

"Freinet sempre acreditou que é preciso transformar a escola por dentro, pois é exatamente ali que se manifestam as contradições sociais" (SAMPAIO, 1989). Crítico da escola "tradicional" e da Escola Nova, Freinet foi criador, na França, do movimento da Escola Moderna.

\section{Criou uma Pedagogia do traba-}

Iho. Para ele, a atividade é o que orienta a prática escolar, e o objetivo final da educação é formar cidadãos para o trabalho livre e criativo, capaz de dominar e transformar o meio e emancipar quem o exerce. Como dever do professor, coloca a criação de uma atmosfera laboriosa na escola, de modo a permitir às crianças fazer experiências, procurar respostas pa- ra suas necessidades e inquietações, ajudando e sendo ajudadas por seus colegas e buscando no professor alguém que organize o trabalho.

Sua pedagogia também é conhecida como a Pedagogia do sucesso. Diferentemente da maioria dos pedagogos modernos, o educador francês não via valor didático no erro. Acreditava que o fracasso desequilibra e desmotiva o estudante, por isso o professor deve ajudá-lo a superar o erro. "Freinet descobriu que a forma mais profunda de aprendizado é o envolvimento afetivo", diz Rosa Sampaio (1989).

Propôs, finalmente, uma Pedagogia do bom senso. Com parábolas inspiradas na sua infância rural, com simplicidade, ele faz reflexões profundas sobre a educação das crianças, como: "É assim que sempre nos enganamos, quando pretendemos mudar a ordem das coisas e obrigar a beber quem não tem sede!" (FREINET, 1991, p. 17) "É lamentável qualquer método que pretenda fazer beber o cavalo que não está com sede. É bom qualquer método que abra o apetite de saber e estimule a poderosa necessidade do trabalho." (Idem, p. 19). Baseada nos interesses e nas vivências das crianças, em suas culturas, atitudes e nos valores na Pedagogia do bom senso, a aprendizagem resulta de uma relação dialética entre ação e pensamento, ou teoria e prática. $O$ professor se pauta por uma atitude orientada tanto pela psicologia quanto pela pedagogia. Assim, o histórico pessoal dos estudantes interage com os conhecimentos novos, e essa relação constrói seu futuro na sociedade.

O mais delicado da nossa tarefa de inovadores não é treinar as crianças para deslancharem com tenacidade no sentido da vida, mas habituar os educadores a se manterem apoiados nos pés, segundo as leis do bom senso e da natureza. (Idem, p. 98) 
Segundo Freinet, a mais eficiente arma para manter vivos nas crianças os traços vitais que tanto interessam à prática educativa é a possibilidade que o educador tem de voltar a ser criança e de utilizar-se, em benefício de seus estudantes, das experiências vividas na sua própria infância. Se o educador for capaz de colocar-se no lugar das crianças e lembrar-se do próprio sentimento quando era elogiado ou criticado, será possível avaliar melhor as consequências de cada gesto e palavra, bem como entender que suas atitudes podem estar marcando, definitivamente, a vida dos seus estudantes.

Considerando sua prática, afirmava que seu único talento como pedagogo talvez fosse a capacidade de ter conservado uma impressão tão total da juventude que isso lhe permitia sentir e compreender, como criança, as crianças que educava. Freinet procurou encarar como se fossem seus próprios problemas as dificuldades apresentadas pelas crianças. Ele chegou a parafrasear a citação de Jesus, afirmando que é necessário tornar-se uma criança para entrar no reino da Pedagogia.

Para ele, a escola era um canteiro de obras, e não um templo. Nela, as crianças deveriam envolver-se, o tempo todo, em trabalhos reais, desafiadores e criativos. A palavra trabalho deveria recuperar seu real significado, sem fragmentações, incluindo seus aspectos intelectuais, manuais e sociais. Neste ambiente de trabaIho integral e integrador, "a criança nunca se cansa de procurar, de experimentar, de realizar, de conhecer e de subir, concentrada, séria, refletida, humana" (FREINET, 1998, p. 84).

Sua pedagogia defende a espontaneidade infantil, por oposição à abstração da cultura escolar burguesa e do magistercentrismo da escola tradicional. Freinet nutria profunda admiração pela sabedoria natural das crianças do campo, que che- gavam à escola carregadas de pequenos insetos, flores e animais do bosque.

\section{III - LIVRE EXPRESSÃO E SEUS SUPORTES}

A concepção de livre expressão de Freinet funda-se na ideia de liberdade de expressão universalmente consagrada a partir das revoluções burguesas que constituíram os estados nacionais, a saber, o direito de qualquer indivíduo manifestar, livremente, opiniões, ideias e pensamentos sem cometer crime. Diante de uma escola tradicional, na qual crianças e jovens deveriam ficar calados e quietos para aprender, isso já seria extremamente inovador. A livre expressão é de vital importância na Pedagogia Freinet.

Os suportes para a livre expressão eram variados. Os estudantes tinham a oportunidade de exercitar a criatividade, exprimindo seus sentimentos, emoções, impressões e reflexões, através das atividades artísticas (desenho, pintura, escultura, colagem, construção, música, mímica, teatro) e das atividades de expressão (como a fala, os textos escritos). Além disso, utilizavam diferentes recursos: máquinas fotográficas, projetor de diapositivos, câmeras, toca-discos, entre outros.

Freinet dedicou a vida a elaborar técnicas de ensino, que funcionavam como canais da livre expressão e da atividade cooperativa, com o objetivo de criar uma nova educação. Debruçou-se nesse trabaIho porque considerava a escola da sua época uma instituição alienada da vida e da família, feita de dogmas e de acumulação estéril de informação e, ainda, em geral, a serviço apenas das classes dominantes. "Freinet colocou professor e estudantes no mesmo nível de igualdade e camaradagem", diz Rosa Sampaio (1989). Embora tenha retirado o tablado do professor, tenha levado uma impressora para dentro da sala, ambiente que era arrumado em ateliês variados e não permanentes, que mudavam em função das necessidades do trabalho e/ou com o interesse da turma, como educador, ele não se o- 
punha às aulas teóricas. No entanto, essas só aconteciam quando uma criança ou o professor explanava sobre assuntos de interesse da classe. Afirmava que o trabaIho do estudante começa sempre nos textos livres, que é a base da pedagogia. Esses são textos efetivamente livres, na forma e no tema. Eles são a expressão do desejo e da curiosidade da criança ao mesmo tempo em que indicam e deixam claramente expressos os temas de seu interesse eleitos como importantes.

A produção do texto livre parte da vontade do estudante e se dá no instante em que essa vontade se manifesta, e não em alguma aula ou momento específico para isso. Segundo os defensores do Método Natural: "só assim ele trará as vantagens que reconhecem essenciais: espontaneidade, vida, criação, ligação íntima e permanente com o meio e a expressão profunda da criança e do jovem." (SAMPAIO, 1989)

A livre expressão é um conjunto de "dizeres" que faz a globalidade do ser, pois é por meio dela que a criança se expressa de forma verdadeira, sincera e espontânea, através da fala, do gesto, da produção de textos. Para que isso aconteça, contudo, a escola deverá representar para ela um ambiente acolhedor e de confiança. O professor deve demonstrar 0 prazer de escutar e/ou ler os textos livres das crianças. A livre expressão é uma possibilidade de as crianças se expressarem e se colocarem no mundo com suas ideias e sentimentos sobre tudo e todos.

Diante dessas possibilidades, destacamos a importância de um espaço escolar que permita essas trocas de experiências, para que o trabalho pedagógico propicie a participação ativa dos estudantes, compreendidos como sujeitos ativos de sua aprendizagem. Para isso, o educador precisa, antes de tudo, conquistar as crianças/estudantes, estabelecendo a convivência num clima de confiança e segurança na sala de aula, e as necessidades e os interesses deverão funcionar como molas propulsoras do processo educativo.

(...) A prática da expressão livre segundo a experiência por tentativas, em Freinet, é considerada etapa indispensável no processo de relações entre criança e o meio, e entendida como trabalho resultante da reflexão e análise (...) instrumento de expressão dos seus pensamentos (PEREIRA, 1997, pp. 8285).

Para Freinet, a comunicação é uma necessidade da criança, e é essa compreensão que justifica a livre expressão como princípio vertebrador na estruturação de suas técnicas de ensino. "Essa comunicação, que se concretiza por meio de diferentes linguagens, tem na expressão verbal seu elemento central" (FREINET, 1979, p. 12).

Segundo Élise Freinet (1979), o elemento central da obra de Célestin Freinet é a livre expressão. Para ele, "a livre expressão não é invenção do cérebro particularmente privilegiado: é a própria manifestação da vida!". Para ele, "A vida prepara-se pela vida" (FREINET, 1979, p. 25).

\section{CONSIDERAÇÕES FINAIS}

[...] Não tenha medo de sujar as mãos, de se machucar com uma martelada, de hesitar nos casos em que a criança mais viva domina a situação, de tatear, de se enganar, de recomeçar. Assim é a vida, e é o esforço que fazemos lealmente, para dominar seus incidentes, que constitui o principal elemento da nossa educação (FREINET, 1996, p. 92).

Afinal não é de hoje que pedagogos ousados pensam e repensam a escola, uma instituição resistente às mudanças. Alguns chegam a dizer que a "escola no- 
va" é uma das coisas mais velha na história da humanidade. Sócrates já dava aula caminhando pelos jardins, na antiguidade. Mas a escola no mundo inteiro parece que, com raríssimas exceções, se mantém nos moldes da escolástica, como dizia Freinet.

Freinet nos desequilibra, nos tira da zona de conforto, com a intensidade não de quem está a produzir teoria pedagógica, mas, sobretudo, pela sua prática, que se realiza como práxis, pois não desvincula teoria da prática, nem prática da teoria. Leva-nos a refletir sobre o real significado de uma pedagogia tradicional, autoritária, longe da vida e fora do contexto de vivência das crianças. Sua crítica à escola tradicional não poupa os professores, quando critica a postura do docente que, sem se preocupar com as "entrelinhas" de uma educação imposta, trabalha com conteúdos compartimentados, em que o mestre manda e os alunos simplesmente obedecem sem se expressar.

\section{REFERÊNCIAS BIBLIOGRÁFICAS}

FREINET, Célestin. A educação do trabaIho. Trad. Maria Ermantina Galvão G. Pereira. São Paulo: Martins Fontes, 1998.

Para uma escola do povo. Trad. Eduardo Brandão. São Paulo: Martins Fontes, 1996.

Pedagogia do bom senso. $3^{a}$ ed. São Paulo: Martins Fontes, 1991.

FREINET, Élise. $O$ itinerário de Celéstin Freinet: a livre expressão na pedagogia Freinet. Trad. Priscila de Siqueira. Rio de Janeiro: Livraria Francisco Alves editora, 1979.

OLIVEIRA, Anne Marie Milon. Célestin Freinet: raízes sociais e políticas de uma proposta pedagógica. Rio de Janeiro: Pa- péis e cópias de Botafogo e Escola de Professores, 1995.

PEREIRA, Francisco de Assis. As contribuições do texto livre na vitalização da sala de aula: uma experiência na escola pública. Natal: DEPED/CCSA/UFRN, 1997. (Tese de Doutorado)

SAMPAIO, Rosa Maria Whitaker F. Freinet - evolução histórica e atualidades. São Paulo: Scipione, 1989.

\section{LIVROS ESCRITOS POR FREINET (EM POR- TUGUÊS)}

FREINET, Célestin. $A$ leitura pela imprensa na escola. Lisboa: Dinalivros, 1977.

A saúde mental da criança. Lisboa: Edições 70, 1978.

As técnicas Freinet da Escola Moderna. Lisboa: Editorial Estampa, 1975.

Conselho aos pais. Lisboa: Editorial Estampa, 1974.

- Educação pelo trabalho. São Paulo: Martins Fontes,1998.

- Ensaio de psicologia sensível. São Paulo: Martins Fontes, 1998.

O jornal escolar. Lisboa: Editorial Estampa, 1974.

O Método Natural I - a aprendizagem da língua. Lisboa: Editorial Estampa, 1977.

O Método Natural II - a aprendizagem do desenho. Lisboa: Editorial Estampa, 1977.

- O Método Natural III - a aprendizagem da escrita. Lisboa: Editorial Estampa,1977. 
vros, 1976.

O texto livre. Lisboa: Dinali-

Para uma escola do povo: guia prático para a organização material, técnica e pedagógica da escola popular. São Paulo: Martins Fontes, 1996.

Para uma escola do povo: guia prático para a organização material, técnica e pedagógica da escola popular. Lisboa: Editorial Presença, 1978.

Pedagogia do bom senso. São

Paulo: Martins Fontes, 1996.

FREINET, Célestin; SALENGROS, R. Modernizar a escola. Lisboa: Dinalivros, 1977.

\section{Publicações SObRe Freinet}

BACLET, Gerard (org.). A pedagogia Freinet por aqueles que a praticam. São Paulo: Martins Fontes, 1976.

BASTOS FILHO, Audir. Simples como Freinet. Composto e impresso na Companhia Brasileira de Artes Gráficas. Rua do Riachuelo,126. Tel: (021) 2252-7396.

BERNARD, Eliade. $A$ escola berta - Freinet no secundário. Lisboa: Livros Horizonte, 1978.

CABRAL, Maria Inêz. De Rosseau a Freinet ou da teoria à prática. São Paulo: Hemus, 1976.

ELIAS, Marisa Del Cioppo. Célestin Freinet: uma pedagogia de atividade e cooperação. Petrópolis, RJ: Vozes, 1997.

De Emílio a Emília: a trajetória da alfabetização. São Paulo: Scipione, 2000.

ELIAS, Marisa Del Cioppo (org.). Pedagogia Freinet: teoria e prática. São Paulo: Papirus, 1996.
FERREIRA, Gláucia de Melo (org.). Palavra de professor(a): tateios e reflexões na prática da pedagogia Freinet. Campinas, SP: Mercado de Letras, 2003.

FREINET, Élise. Nascimento de uma pedagogia popular. Trad. Rosália Cruz. Lisboa: Editorial Estampa, 1978.

O itinerário de Célestin Freinet. a livre expressão na pedagogia Freinet. São Paulo: Francisco Alves, 1979.

KIRINUS, Glória. Criança e poesia na pedagogia Freinet. São Paulo: Paulinas, 1998.

MAURY, Liliane. Freinet e a pedagogia. São Paulo: Martins Fontes, 1993.

MINICUCCI, Agostinho. Da psicologia soviética à pedagogia Freinet. Goiânia: Dimensão, 1992.

MORAIS, Maria de Fátima (org.). Freinet $e$ a escola do futuro. Recife: Bagaço, 1997.

NASCIMENTO, Maria Evelyna Pompeu do. A pedagogia Freinet. natureza, educação e sociedade. Campinas/SP: Editora da UNICAMP, 1995.

NUNES, Antônio. Freinet: a actualidade pedagógica de uma obra. Porto: Edições ASA, 2002.

OLIVEIRA, Anne Marie Milon. Célestin Freinet: raízes sociais e políticas de uma proposta pedagógica. Rio de Janeiro: Papéis e Cópias de Botafogo Ltda., 1995.

PAN, Mariza. Ser integral: uma experiência na pedagogia Freinet. Curitiba: Colégio Integral, 2003.

PRISTA, Rosa Maria; COELHO, Valéria. Freinet em movimento. Vassouras/RJ: Secretaria Municipal de Vassouras e I NucleRio, 2000. 
SAMPAIO, Rosa Maria Whitaker. Freinet: evolução histórica e atualidades. São Paulo, Scipione, 1989.

SANTOS, Maria Lúcia dos. $A$ expressão livre no aprendizado da língua portuguesa - pedagogia Freinet. São Paulo: Scipione, 1991.

SMOLKA, Ana Luiza B (org.). Centenário de nascimento de Piaget, Freinet, $V y$ gotsky e Jakobson. Campinas, SP: Editora da UNICAMP, 1998.

VRETENAR, Nerina; CAVINATO, Giancarlo. Rumo a uma nova alfabetização. In: PÈREZ, F.C.; GARCIA, J. R. (orgs.) Ensinar ou aprender a ler $e$ a escrever? Aspectos teóricos do processo de construção significativa, funcional e compartilhada do código escrito. Porto Alegre: ARTEMED, 2001. 